\title{
APPLICATION OF CRYOGENIC ENERGY STORAGE (CES) IN DISTRIBUTED RENEWABLE GENERATION
}

\author{
Dmitrijs Rusovs, Lubova Parsikova \\ Riga Technical University, Latvia \\ dmitrijs.rusovs@rtu.lv, lubova.parsikova@rtu.lv
}

\begin{abstract}
Application of energy storage becomes a common solution for improvement of renewable generation system performance. Nowadays thermal energy storage by water sensitive heat provides limited flexibility in operation of generation facilities. Storage capacity for this type of energy accumulation accounts only for 35-55 $\mathrm{kWh} \cdot \mathrm{m}^{-3}$. For example, if a combined heat power (CHP) generator had the output of $100 \mathrm{MWe}$, then the heat energy for accumulation will be at least equal to this value. Waste heat will fill the tank with a volume of $2000 \mathrm{~m} 3$ in only one hour. Another limitation is low efficiency to convert heat energy from thermal storage to electrical energy. Due to that great interest is in liquid air energy storage (LAES). Cryogenic technologies nowadays represent widely used industrial tools. However, the first pilot plant operation demonstrates very low round trip efficiency. Intensive effort of many researches encourages further development of cryogenic energy storage (CES). Various simulations of the process and combination with another energy technology predict round trip efficiency up to $50 \%$ and more. Our research was focused on two aspects: firstly, to apply for process design in coordinate pressure-enthalpy widely used in refrigeration and secondly investigate the possible benefit of joint operation bioCHP and CES. The proposed process flowsheet employs Kapitza cycle for air liquefaction and single stage compression, and single stage expansion. As results of considerations the equation was developed for calculation of specific energy for air liquefaction. Calculation resulted in specific work value of $2223 \mathrm{~kJ}^{\mathrm{kg}} \mathrm{kg}^{-1}$. The eEnergy recovery process from CES was based on liquid air pressure increase up to 60 bar and then superheating to $350{ }^{\circ} \mathrm{C}$ with application of steam from turbine extraction. Since optimum combination of parameters was not investigated, the round trip efficiency was only $10 \%$. Nevertheless, our research reveals that just $6 \%$ of total steam flow from extraction of the turbine with rated capacity $4 \mathrm{MW}$ will ensure $1 \mathrm{MW}$ output in the air turbine. 12 cubic meters of liquid air can generate electrical power of $1 \mathrm{MW}$ during one hour.
\end{abstract}

Keywords: energy storage, cryogenic engineering, Kapiza process, renewable distributed generation.

\section{Introduction}

Since climate issue became an ambitious global goal, the fast growing demand for efficient energy storage facilities creates new opportunity for already well-known technologies. For example, cryogenic engineering had already almost hundred years of experience for industrial scale commercial application. Gas liquefaction process widely used in modern engineering, lot of mature technologies and components available for different scales of production [1]. Therefore, it was not surprising that scientists and engineers try to use cryogenic methods for energy storage already few decades. The first well known pilot plant trial demonstrates round trip efficiency only $8 \%$ [2], nevertheless this experiment caused huge interest and output in few tens of various theoretical and simulation research papers in this area. Scientists' rally resulted in proposal for various technologies combination, like trigeneration, organic Rankin cycle (ORC), Liquid Natural gas, High Grade Cold Storage and others with achievement of round trip efficiency more than $50 \%$ in theoretical simulations $[3 ; 4]$.

Most or researchers are using Aspen HYSYS software for simulation of the gas liquefaction process. Our paper offers to propose to use other tools for design of air liquefaction and energy recovery though air expansion. We suggest drawing a process in pressure-enthalpy thermodynamic chart. This type of chart is very common for refrigeration process consideration. Air is known as refrigerant agent R729. Data for air property are easy available from open source CoolPack v1.5.0 for wide range of pressure and temperature [5].

There are two key performance parameters for every liquefaction plant.

1. Specific energy consumption $S$ defined as the ratio of the consumed energy to mass of the produced liquid gas:

$$
S=\frac{W_{\text {compressor }}-W_{d}}{m_{\text {liquidair }}}, \mathrm{kJ} \cdot \mathrm{kg}^{-1}
$$

where $W_{\text {compressor }}$ and $W_{d}-$ work consumption by the compressor and detander. 
2. Liquid yield defined as the ratio of compressed gas mass to the mass of liquid gas. For cryogenic energy storage the value of round trip efficiency is crucial important defined as

$$
T=\frac{W_{\text {airturbine }}-W_{\text {cryopump }}}{W_{\text {compressor }}-W_{d}+Q_{\text {sup erheating }}},
$$

where $W_{\text {airturbine }}-$ expansion work,

$W_{\text {cryopump }}$ - work of liquid air pumping into evaporator and super heater;

$Q_{\text {superheating }}$ is the amount of energy used to increase the temperature of air before expansion.

It is definitely not fair to account thermal energy for superheating along with electrical or mechanical work of the compressor. But this calculation will reveal superheating efficiency for round trip performance.

There are a number of well-known thermodynamic cycles used for gas liquefaction: Linde and Linde-Hampson, Claude and Kapitza. Table 1. represents a comparison of the cycle performance obtained by simulation calculation and by observation of the real scale process.

Table 1

Comparison of different liquefaction systems performance

\begin{tabular}{|c|c|c|}
\hline Gas liquefaction cycle and parameters & $\begin{array}{c}\text { Specific energy } \\
\text { consumption, in } \mathbf{k J} \cdot \mathrm{kg}^{-1}\end{array}$ & Liquid yield \\
\hline Precooled simple Linde system, observed [1]. & 5580 & - \\
\hline Claude system, observed [1]. & $3580-3255$ & - \\
\hline Claude system, $\mathrm{P} 2=40$ bar $[1 ; 6]$. & $2020-2600$ & 0.189 \\
\hline Kapitza (two stage) [6] & 2560 & - \\
\hline $\begin{array}{l}\text { Commercial scale liquification plant. High } \\
\text { View [7] with High Grade Cold Storage }\end{array}$ & 1440 & - \\
\hline
\end{tabular}

Most of the liquefaction systems implemented in the air liquefaction plant employ the Kapitza cycle, a modified version of the Claude cycle because of less equipment demanded.

With purpose to simulate performance of the air liquefaction process Kapitza cycle was selected with a single compression stage because of low compression ratio applied. In the presented paper we consider performance when the pressure after compressor was only 6 bar.

It seems that there are few main ways how to increase round trip efficiency: the first one is to use as much as possible hot and cold thermal energy storages with saved energy return in the process, the second way assumes to improve performance of compressors, expansion turbines and also increase scale of the plant. In addition, it is possible to increase total performance by improving of the discharge phase efficiency based on the specific work output during expansion or air measured in $\mathrm{kJ} \cdot \mathrm{kg}^{-1}$.

Indeed, CAPEX parameter represents the capital cost of CES in EUR/kW and it is already in the range from 900 to 6000, what is more expensive than the compressed air storage CAES (CAPEX $=970$ 5000 ) and the pumped hydro energy storage PHS (CAPEX $=600-2000)$.

The target of the paper is to develop a simple and transparent method to evaluate the efficiency of low pressure CES operation with small scale Combined Heat Power (CHP) plant operation.

\section{Materials and methods}

The time shift between generation and consumption becomes very important in case of distributed generation, therefore, energy storage should be integrated in CHP [8,9]. At the present moment in Latvia two big thermal energy storages are created in Jelgava for Fortum bio CHP (5000 cubic meters and $170 \mathrm{MWh}$ ) and in Salaspils for thermal solar panel field with total volume of 8000 cubic meters and $418 \mathrm{MWh})$ [10; 11].

As we can see, the specific capacity of this thermal energy storage is about 34 to $52 \mathrm{kWh} \cdot \mathrm{m}^{-3}$ and it is possible to convert this energy to electrical with efficiency less than 10-15\% by ORC. Along with this, the electrical energy capacity for CES by using liquid air can reach up to $200 \mathrm{kWh} \cdot \mathrm{m}^{-3}$ [7].

Our proposed system includes a small scale water steam turbine (case study) with electrical rated power of $4 \mathrm{MW}$, when the steam flowrate is 21.7 tons per hour in point 11 for Fig. 1, where the steam 
temperature and pressure are $56 \operatorname{bar}(a)$ and $467 \mathrm{C}$. Inlet enthalpy of steam is $3348 \mathrm{~kJ} \cdot \mathrm{kg}^{-1}$. The outlet of turbine operates at 1 bar(a) and temperature about $100 \mathrm{C}$.

The energy balance described by the air super heater A in Fig.1 can be following steam from turbine extraction 12 at pressure $2.6 \mathrm{MPa}$ and enthalpy enter in A and left as condensate at temperature $250{ }^{\circ} \mathrm{C}$ (saturated condition) with enthalpy $1085 \mathrm{~kJ} \cdot \mathrm{kg}^{-1}$. However, the air flow of 10 tons per hour needs energy of $1200 \mathrm{MJ}$ to increase the temperature from $200 \mathrm{C}$ to $350{ }^{\circ} \mathrm{C}$. Therefore, only $600 \mathrm{~kg}$ per hour of water steam from turbine extraction ensure requested warming and the total energy output of the air turbine will be around $1 \mathrm{MW}$, if the air rate will be 10 tons per hour. Indeed, 120 cubic meter CES can ensure additional power of $1 \mathrm{MW}$ during ten hours. The considered steam extraction from the turbine will be only $3 \%$ of the rated steam flow.

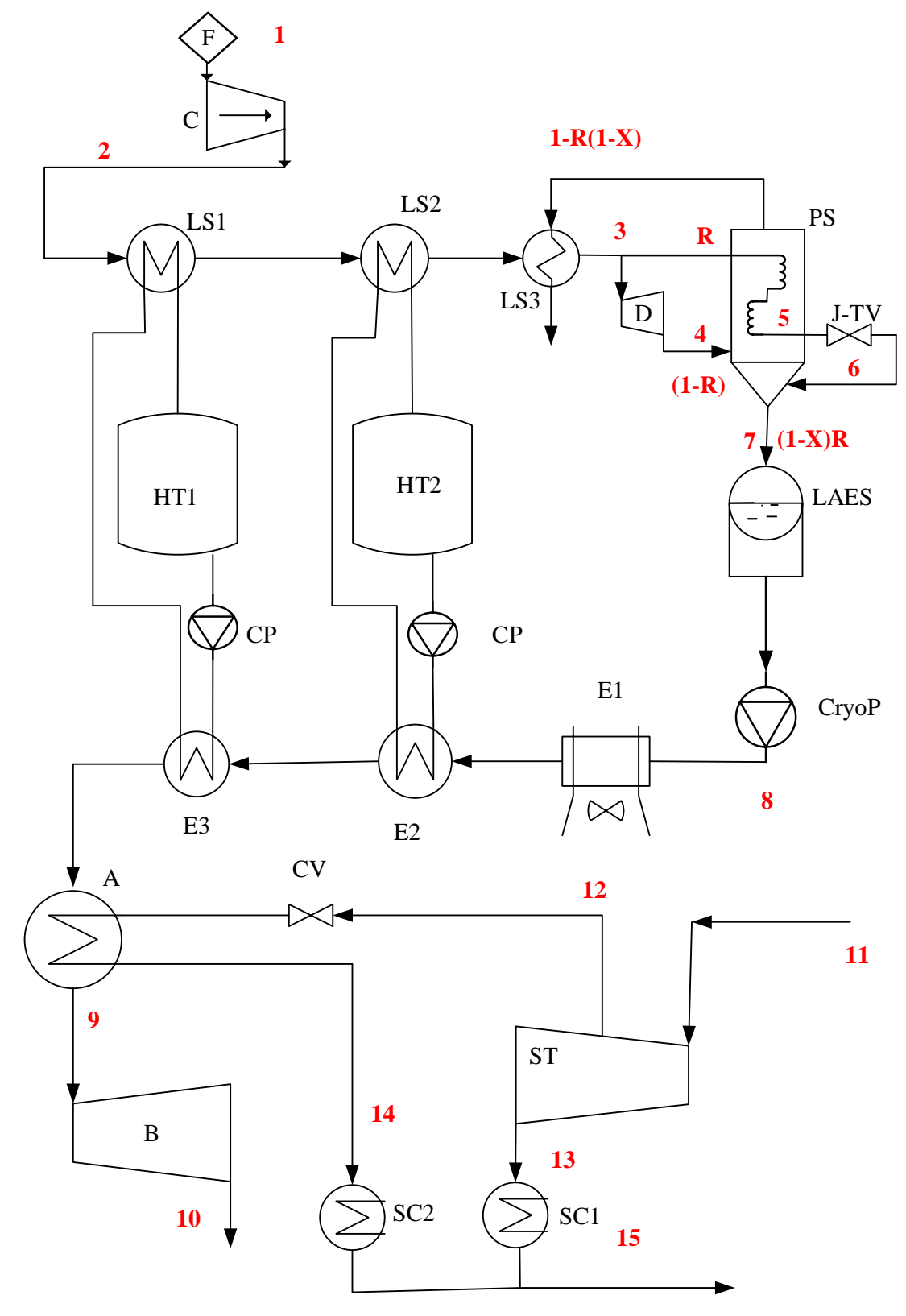

Fig. 1. Flow chart of the proposed LAES-BCHP system: 1 - ambient air inlet though filter (F); 2 - Compressed air after compressor (C) cool down in two heat exchanger (LS1 and LS2) with hot air energy storage in HT1 and HT2; 3 - cold air before expansion in detander (D) fraction (1-R) and entrance in phase separator (PS) fraction R; 4 - air after expansion in detander enters in PS and cools the air to point 5 before throttling in Joule-Thomson valve (J-TV), after isenthalpic pressure drops part of air $\mathrm{R}(\mathrm{x}-1)$ is converted into liquid and collected in the low pressure liquid air energy storage (LAES) 
Heat exchanger LS3 ensures low air temperature in 3 before expansion in the detander. During the energy recovery phase from liquid air cryogenic pump will increase the liquid air pressure to point 8 up to 60 bar or more. Two parallel circulation pumps (CP) provide energy recovery from storage HT1 (thermal oil) and storage HT2 (hot water) for air superheating in the heater (E2 and E3) after its evaporation in the heater (E1). Additional superheating up to temperature in point 9 for compressed air can be provided in the water steam warmed heat exchanger (E3). After that hot compressed air expands in the air turbine (B). The bio cogeneration plant based on water steam Rankine cycle produces electrical energy in the turbine (ST). The water steam from the turbine extraction point 12 flows through the control valve (CV) into the air super heater (A). Steam condensing energy after the condenser SC1 and SC2 should be used for heating in cogeneration mode of operation.

With the purpose to evaluate the performance of the liquefaction part and recovery plant output for CES we suggest to consider the process in the air R729 pressure - enthalpy diagram.

The main points for the air liquefaction process and subsequent gasification and expansion are presented in Fig. 2 and Table 2.

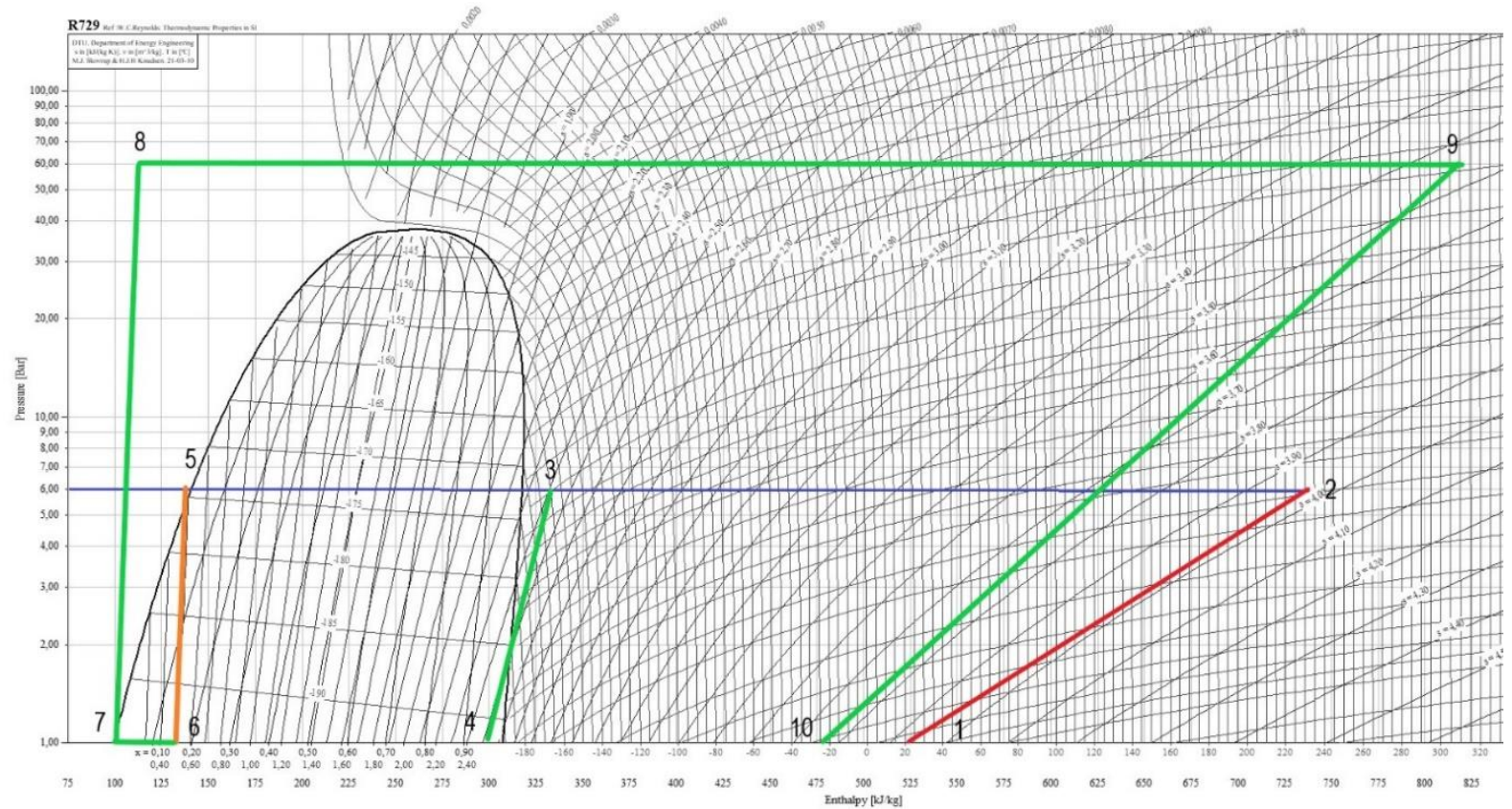

Fig. 2. Pressure - enthalpy diagram for R729 (air); air liquefaction (Kapiza process1-2-3-4-5-6) with energy recovery from liquid air by evaportaion (7-8-9) and expansion in turbine (9-10)

Characteristic point parameters in liquid air storage process diagram

Table 2

\begin{tabular}{|c|c|c|c|c|}
\hline $\begin{array}{c}\text { Pressure, } \\
\text { bar }\end{array}$ & $\begin{array}{c}\text { Enthalpy, } \\
\mathbf{k J} \cdot \mathbf{k g}^{-1}\end{array}$ & $\begin{array}{c}\text { Entropy, } \\
\mathrm{kJ} \cdot \mathrm{kg}^{-1} \cdot \mathbf{K}^{-1}\end{array}$ & $\begin{array}{c}\text { Temperature, } \\
{ }^{\circ} \mathrm{C} \\
\end{array}$ & $\begin{array}{c}\text { Isentropic } \\
\text { efficiency \% }\end{array}$ \\
\hline 1 & 521 & 3.9 & 20 & - \\
\hline 6 & 730 & 3.96 & 226 & 85 \\
\hline 6 & 323 & 2.4 & -160 & - \\
\hline 1 & 300 & 2.54 & -191 & 70 \\
\hline 6 & 141 & 0.49 & -174 & - \\
\hline 1 & 141 & 0.56 & -193 & - \\
\hline 1 & 100 & 0.04 & -193 & - \\
\hline 60 & 109 & 0.055 & -192 & 85 \\
\hline 60 & 823 & 3.46 & 315 & - \\
\hline 1 & 473 & 3.74 & -29 & 85 \\
\hline
\end{tabular}

The air liquefaction process selected the starting point 1 (ambient air), then the pressure increased up to 6 bar. For the air compressor C, turbine B and cryogenic pump CryoP the isentropic efficiency of 
$85 \%$ was used, but for the expander D the isentropic efficiency of $70 \%$ was used. The temperature for the point $3-160{ }^{\circ} \mathrm{C}$ was accepted according to recommendation for Kapitza system operation. It should be noted that cold energy after air expansion could be used in purpose to decrease the compression work for the cycle.

The heat balance of the liquefaction plant will reveal excess heat energy because the compressed air had bigger mass than the liquid air flow, which had to be warmed up. The detailed calculation of heat balance in the liquefaction plant is not included in this step of the work, but it will definitely bring additional energy output of the storage.

\section{Results and discussion}

Definition of recirculation fraction is possible to be derived from the energy balance of the phase separator PS in Fig. 1. There are two inlet flows: fraction from the turbo detander (1-R) and through the J-T valve (R). The inlet energy will be balanced by the outlet flow of the cold air gas fraction 1-R - (1$\mathrm{x})$ leaving PS and the liquefied air part $(1-\mathrm{x}) \cdot \mathrm{R}$ to LAES. This balance resulted in the following equation for recirculation fraction

$$
R=\frac{1}{1+(1-x) \frac{h_{3}-h_{7}}{h_{3}-h_{4}}},
$$

where $(1-x)$ - the liquid air yield after cold air expansion from the J-T valve.

The value of the steam fraction $\mathrm{x}$ is easy to calculate by the following expression, $h_{i}$ with $i$ value from 1 to 10 represent the value of air enthalpy, $\mathrm{kJ} \cdot \mathrm{kg}^{-1}$, according to Table 2 and Fig. 2 . Actually, $h_{5}=h_{6}$ because of the isenthalpic throttling process.

$$
x=\frac{h_{5}-h_{7}}{h_{4 S}-h_{7}},
$$

where $h_{4 S}-$ enthalpy of saturated steam of air at storage temperature and pressure.

The work consumption per mass unit of air liquefaction is possible to calculate as

$$
S-\frac{\left(h_{2}-h_{1}\right)-\left(h_{3}-h_{4}\right)}{(1-x) R} .
$$

In three equations there are three unknown values. After definition of them it is possible to estimate round trip efficiency as follows

$$
T=\frac{(1-x) R\left(h_{9}-h_{10}\right)}{\left(h_{2}-h_{1}\right)+(1-x) R\left(h_{8}-h_{7}\right)-(1-R)\left(h_{3}-h_{4}\right)} .
$$

The result of calculation by equation (5) according to the proposed flowchart and selected parameters demonstrates good compatibility with the value of specific energy consumption from Table 1 or $2223 \mathrm{~kJ}$ per kilogram of liquid air. The value of the recirculation fraction was about $11 \%$ what is lower than for simulation results in [6], but our calculation was done at quite low pressure after the air compressor - only 6 bar.

The liquid yield is easy to calculate as

$$
Y=(1-x) R .
$$

Due to the low recirculation rate, the value of the liquid yield was only $9,4 \%$. Therefore, $\mathrm{S}$ round trip efficiency accounts for $15 \%$ in equation (5) in case, if additional heat for superheating to $350{ }^{\circ} \mathrm{C}$ is not taken in account.

In case of calculation of S according to equation (2), the round trip value will decrease to $10 \%$.

The presented results should be considered as only preliminary estimation with the main value of easy transparent methods of calculation and suggested coupling of CAS with bio CHP.

The system of equations (1-7) gives background for liquid air storage simulation with a target to find the best combination of parameters to ensure the maximum possible round trip efficiency value. 


\section{Conclusions}

1. The design of liquid air production by Kapitza cycle and energy recovery by expansion of superheated air was proposed in coupling with bio CHP based on the water steam Rankine cycle. Actually, instead of the water steam turbine it is possible to use another thermal engine, for example, biogas internal combustion etc.

2. The process design was done in the pressure-enthalpy chart for air. Transparent and clear estimations were done. Characteristic point values are presented in tables. According to our calculation, the specific energy for air liquefaction was around $2223 \mathrm{~kJ} \cdot \mathrm{kg}-1$, this value had good compatibility with another simulation of this process.

3. The energy consumed for gas liquefaction depends on the scale of the plant and already long time is more or less a constant value. To improve the round trip efficiency for CES it is important to find the best combination of various parameters, like the pressure after the cryo pump, temperature of air before the turbine, multistage compression and expansion.

4. Combination of CES with the thermal engine in CHP will reveal a possibility for additional stability for generation in the distributed network; according to our estimation only $6 \%$ of total flowrate from the water steam turbine can ensure up to $25 \%$ power increase by using of the air turbine. Only 12 cubic meters of liquid air will be sufficient to ensure $1 \mathrm{MW}$ generation during one hour.

\section{Acknowledgements}

This research is funded by the Ministry of Economics of the Republic of Latvia, project "Innovative smart grid technologies and their optimization (INGRIDO)", project No. VPP-EM-INFRA-2018/10006 .

\section{References}

[1] Timmerhaus K.D., Flynn T.M., Cryogenic Process Engineering. Springer Science + Business Media, 1989, $614 \mathrm{p}$.

[2] Morgan R., Nelmes S., Gibson E., Brett G. Liquid air energy storage e analysis and first results from a pilot scale demonstration plant. Appl Energy, vol.137, 2015, pp.845-853.

[3] Sciacovelli A., Vecchi A., Ding Y. Liquid air energy storage (LAES) with packed bed cold thermal storage - From component to system level performance through dynamic modelling. Appl Energy, vol.190, 2017, pp. 84-98.

[4] Guizzi GL., Manno M., Tolomei LM., Vitali RM. Thermodynamic analysis of a liquid air energy storage system. Energy, vol.93, 2015, pp. 1639-1647.

[5] CoolPack Software v1.5.0 [online] [21.03.2021] Available at: https://www.ipu.dk/products/coolpack/

[6] Borri E., Tafone A., Romagnoli A., Comodi G. A preliminary study on the optimal configuration and operating range of a "microgrid scale" air liquefaction plant for Liquid Air Energy Storage. Energy Convers Manage, vol. 143, 2017, pp. 275-285.

[7] Borri E., Tafone A., Romagnoli A., Comodi G. A review on liquid air energy storage: History, state of the art and recent developments. Renewable and Sustainable Energy Reviews, Vol. 137, March 2021, p. 110572.

[8] Sauhats A., Kozadajevs J., Dolgicers A., Zalitis I., Boreiko D. (2019). Thermal energy storage for CHP in power market conditions. In 2019 16th International Conference on the European Energy Market (EEM), 18-20 September 2019. Ljubljana, Slovenia

[9] Sorocins A., Nagla J., Zentins V. District Heating Simulation Model Development to Solve Optimization Problems in the Market Conditions. In: 2020 IEEE 61st International Scientific Conference on Power and Electrical Engineering of Riga Technical University (RTUCON 2020), Latvia, Riga, 5-6 November, 2020. Piscataway: IEEE, 2020, pp. 1-4

[10] 15 MW SDH plant inaugurated in Latvia, [online] [21.03.2021] Available at: https://www.solarthermalworld.org/ news/15-mw-sdh-plant-inaugurated-latvia

[11] Jelgava CHP plant, [online] [21.03.2021] Available at: https://www.fortum.com/about-us/ourcompany/our-energy-production/our-power-plants/jelgava-chp-plant 